\title{
STUDY ON THE EFFECT OF ASPARAGUS EXTRACTS ON PROMOTING METABOLISM OF THE BODY
}

\author{
Xiaohong LI ${ }^{1}$, Caili SUN, Tuanting ZHANG \\ Department of Physical Education, Xi'an University of Architecture and \\ Technology, Xi' an, 710055, China
}

\begin{abstract}
This study aims to analyze the effective ingredients of asparagus extracts and the changes of vitamins content in mice body after the intake of asparagus extracts, thus to conclude the effect of asparagus extracts on body metabolism during exercises. Extracts were made into different concentrations of solution and given to the mice by intragastric administration. The content of micro-elements and vitamin groups in the mice body before and after the drug administration were detected respectively and biochemical index parameter values before and after swimming were measured respectively. Results showed that, $20 \mathrm{~min}$ after the drug administration, the content of blood lactic acid of the mice in the swimming experiment group decreased significantly. Besides, the content of muscle glycogen decreased and correspondingly the content of hepatic glycogen increased significantly (experiment group one and two: $p<0.01$; experiment group 3: $p<0.05$ ). Thus the ethanol extract solution of asparagus can effectively improve body metabolism.
\end{abstract}

Keywords: asparagus extracts; exercise body; metabolism promotion

\section{INTRODUCTION}

The asparagus is a kind of liliaceous and perennial plant, which is also a familiar dish on the table (Zhao et al., 2012). The edible part of asparagus is the tender stem that tastes soft and delicious, which can enhance appetite and help digestion. Therefore, asparaguses are rich in nutrients and have high medicinal values (Jia, 2007). As a kind of expensive vegetable that can be both made into dishes and medicines, wild asparaguses are taken as the top grade vegetable in Sheng Nong's Herbal Classic (Ju, 2011).

In recent years, studying the effect of the extracts of fruits and vegetables on improving physical strength and resisting fatigue of athletes has become a new

\footnotetext{
${ }^{1}$ Corresponding author. Mailing address: Xiaohong Li, Department of Physical Education, Xi'an University of Architecture and Technology, NO. 13, Yan Ta Road, Xi'anCity, Shaanxi Province, China. E-mail: lixiaohongl@hotmail.com
} 
trend (Xie et al., 2004). Swimming and pole-climbing experiments of mice verified that after the administration of asparagus extracts solution, mice showed fatigue-resistant, anoxia-resistant, cold-resistant and heat-resistant reactions. In addition, the asparagus extracts solution could prevent the flu. Another piece of evidence was that the ancient Romans used the asparagus to wish warriors victories (Sun et al., 2012). Therefore, it is of great significance for athletes to take asparaguses or derivative products of asparaguses. At present, some fruits and vegetables extracts have been developed as antifatigue nutriments in China and foreign countries (Zhang and Liu, 2013). For example, the asparagus yellow rice wine, asparagus noodles, canned asparagus, asparagus SOD oral liquid, instant asparagus extracts and compound vegetable juice, etc. The asparagus contains various kinds of active constituents, such as saponins, polysaccharide, fatty acid, amino acid and multiple kinds of microelements, etc. The content of vitamins in the asparagus is usually 2-5 times that of normal vegetables. An amount of $100 \mathrm{~g}$ of fresh asparagus contains rich carotene, vitamin B1, vitamin B6 and vitamin C. There are as many as 15 kinds of mineral elements in the asparagus, some of which have extremely high content, such as calcium, iron and iodine, etc. The content of selenium in micro-elements of asparaguses reaches up to $0.95 \mathrm{mg}$. Moreover, there are about 17 kinds of amino acid in asparaguses and the content reaches up to $42.26 \mathrm{mg} / \mathrm{kg}$. The main kind of amino acid is asparaginic acid, accounting for about $20 \%$ of the total content of amino acid. The glutamic acid content accounts for about $15 \%$ of the total content. The content of leucine, isoleucine, alanine and lysine is also very high. The sugar content in the asparagus is high which accounts about $14.91 \%$. Moreover, it increases as the asparagus grows (Tian et al., 2013).

Therefore, studies on the active ingredients of asparagus extracts have caused high attentions from researchers in China and abroad (Zhang et al., 2013). In this study, experiments were carried out to verify the effect of ethanol extract solution of asparagus on promoting the body metabolism.

\section{MATERIALS AND METHODS}

\section{Preparation of ethanol extracts of the asparagus}

An asparagus root or stem was dried in a drying oven at a constant temperature $\left(40^{\circ} \mathrm{C}\right)$. Then it was smashed and sieved to get rid of impurities. An amount of $300 \mathrm{~g}$ of asparagus powder was added with $80 \%$ ethyl alcohol and an appropriate amount of distilled water orderly; the solid-liquid ratio was 1:25. The extraction was performed at $65^{\circ} \mathrm{C}$ for 2 hours and the process was repeated twice. After that, the extracting solution was combined and then concentrated at $50{ }^{\circ} \mathrm{C}$ using a rotary evaporator. After cooling and drying, the ethanol extract solution of the asparagus was finally obtained (Tang et al., 2011). 


\section{Composition measurement of asparagus ethanol extracts}

Phenol-sulfuric acid method was used to measure the total sugar content. The method of vanillin-perchloric acid was used to measure the total content of saponin, and the high performance liquid chromatography (HPLC) was adopted for the measurement of amino acid content. The obtained amino acid solution was hydrolyzed into 2,4-dinitro-fluorobenzene derivatization solution. Then the chromatography was used to measure the content of free amino acid. The content of vitamin A was measured by ultravioletvisible absorption spectroscopy and the content of vitamin B complex was measured using HPLC. Microtitrimetry was used to measure the content of vitamin $C$ and the content of crude protein (iron, zinc, selenium and copper) was measured by kjeldahl determination.

\section{Pretreatment of samples}

The obtained ethanol extract solution of asparagus was added with the distilled water and diluted to concentrations of $4 \%, 7 \%$ and $10 \%$ respectively.

\section{Experimental design}

(1) Swimming experiment

Forty healthy male adult mice of the same age were divided into four groups according to the body weight, ten mice in each group. The four groups included one control group and three experimental groups. Mice in the control group were fed normally. Mice in experimental group one were given $4 \%$ ethanol extract solution of asparagus by intragastric administration, while the mice in experimental group two and three were given $7 \%$ and $10 \%$ ethanol extract solution of asparagus by intragastric administration. Fifteen minutes after the administration, all the mice swam in water $\left(25^{\circ} \mathrm{C}-35^{\circ} \mathrm{C}\right)$ for $20 \mathrm{~min}$. After that, mice rested for $10 \mathrm{~min}$ and received blood sampling. Blood samples of big mice were collected from the caudal vein, while those of small mice were collected by pulling out the eyeball for measurement of blood lactic acid content ( $\mathrm{Hu}$ et al., 2007). After that, five mice in each group were killed immediately and their fresh livers and muscles on hind legs were collected. After the cleansing using normal saline, the collected livers and muscles were blotted up using filter papers. An amount of $300 \mathrm{mg}$ liver and muscle was precisely taken respectively and added with normal saline to prepare $10 \%$ tissue homogenate. The mixture was centrifuged in $2000 \mathrm{rpm}$ for $10 \mathrm{~min}$. Then the supernatant was collected for measurement of hepatic glycogen and muscle glycogen content. The rest mice continued to swim for $50 \mathrm{~min}$ and the second time of extraction and measurement of blood lactic acid were performed (Zhu, 2003). Fifty minutes after the swimming, the second time of the measurement of lactic acid content was performed. 
(2) Experiment two

Forty healthy male adult mice of the same age were divided into two groups randomly which were the control group and the experimental group, 20 mice in each group. Mice in the control group were fed normally while the mice in the experimental group were given the asparagus extract solution. Then the content of calcium, vitamins and micro-elements, such as iron, zinc and selenium, etc., in the body of all mice were measured. After a month, the above step was repeated once to obtain new data.

\section{Data analysis}

The database of experimental data was established using Excel. Software SPSS18.0 was used for data statistics. Data were expressed by mean \pm SD. Besides, variance analysis and t-test between groups were adopted; $p<0.05$ indicated statistical significance.

\section{RESULTS AND DISCUSSIONS}

\section{Analysis of bio-active constituents of asparagus extracts}

As shown in Table 1 and Figure 1, the effective constituents of ethanol extracts of asparaguses are rich in saponin and polysaccharides, in which the content of saponin accounts for $18.3 \%$, the content of polysaccharides accounts for $14.91 \%$ and the content of fat accounts for only $2.04 \%$. Moreover, the content of free asparaginic acid and glutamic acid is extremely high in amino acids.

Table 1. Effective constituents and their content in ethanol extracts of asparaguses

\begin{tabular}{ccc}
\hline Serial number & Name of effective constituent & Content $(\mathrm{mg} / 100 \mathrm{~g})$ \\
\hline 1 & Vitamin B1 & 1.56 \\
2 & Vitamin B2 & 4.67 \\
3 & Vitamin C & 21.13 \\
4 & B-carotene & 3.97 \\
5 & Calcium & 38.88 \\
6 & Iron & 17.01 \\
7 & Zinc & 35.02 \\
8 & Selenium & 0.95 \\
9 & Copper & 1.98 \\
10 & Asparaginic acid & 2400 \\
11 & Glutamic acid & 2730 \\
12 & General flavone & 97 \\
\hline
\end{tabular}




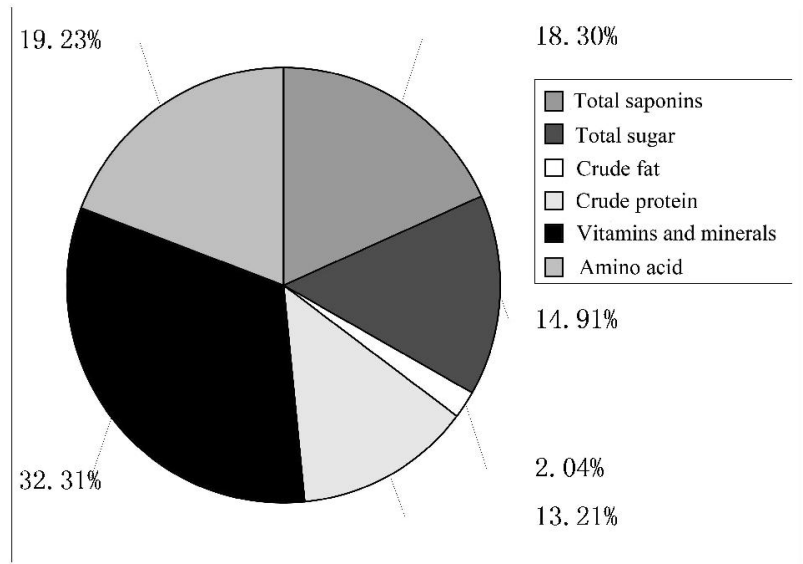

Figure 1. Proportions of the active constituents in asparagus extracts

\section{Measurement of the content of calcium, vitamins and micro-elements in mice body}

The body metabolism is closely related to the calcium, vitamins and microelements in the body. Studies showed that the high content of these constituents could promote the body metabolism (Luan et al., 2007). Table 2 shows that, after the intake of asparagus extract solution, the content of microelements, vitamins and calcium in the body of mice increases significantly.

Table 2. The content of calcium, iron, zinc and selenium in mice in the control group and experimental group

\begin{tabular}{|c|c|c|c|c|c|}
\hline & $\begin{array}{c}\text { Calcium } \\
(\mathrm{g})\end{array}$ & $\begin{array}{c}\text { Iron } \\
(\mathrm{mg} / \mathrm{g})\end{array}$ & $\begin{array}{c}\text { Zinc } \\
(\mathrm{mg} / \mathrm{g})\end{array}$ & $\begin{array}{c}\text { Selenium } \\
(\mathrm{mg} / \mathrm{g})\end{array}$ & $\begin{array}{c}\text { Vitamins } \\
(\mathrm{mg} / 100)\end{array}$ \\
\hline $\begin{array}{c}\text { Before drug } \\
\text { administration }\end{array}$ & 12.5 & 20.30 & 6.33 & 0.87 & 3.73 \\
\hline $\begin{array}{c}\text { After drug } \\
\text { administration }\end{array}$ & 18.3 & 26.54 & 7.21 & 1.05 & 6.84 \\
\hline
\end{tabular}

High content of these constituents helps to build an alkaline physical environment, which can promote the metabolism of the body. Thus, the solution of asparagus extracts can promote the body metabolism.

\section{Content changes of blood lactic acid, hepatic glycogen and muscle glycogen before and after swimming}

Because the body was in a state of motion in a longtime, thus the content of blood lactic acid should be extracted twice in two different periods, thus to make the experimental results be more convincing. The influence of ethanol extracts of asparaguses on the loaded-swimming time of mice is given in Table 3. 
Table 3. Influence of ethanol extracts of asparaguses on the loaded-swimming time of mice $(n=10$, mean \pm SD)

\begin{tabular}{ccccc}
\hline Group & $\begin{array}{c}\text { Dosage } \\
\text { (mg/kg) }\end{array}$ & $\begin{array}{c}\text { Exhaustion } \\
\text { time after a } \\
\text { week (S) }\end{array}$ & $\begin{array}{c}\text { Exhaustion time } \\
\text { after 2 weeks (S) }\end{array}$ & $\begin{array}{c}\text { Exhaustion time } \\
\text { after 3 weeks(S) }\end{array}$ \\
\hline Control group & 0 & $309 \pm 102$ & $310 \pm 100$ & $331 \pm 138$ \\
\hline $\begin{array}{c}\text { Experimental } \\
\text { group one }\end{array}$ & $4 \%$ & $399 \pm 184$ & $550 \pm 180^{* *}$ & $565 \pm 180^{* *}$ \\
\hline $\begin{array}{c}\text { Experimental } \\
\text { group two }\end{array}$ & $7 \%$ & $367 \pm 136$ & $491 \pm 222^{*}$ & $546 \pm 312^{*}$ \\
\hline $\begin{array}{c}\text { Experimental } \\
\text { group three }\end{array}$ & $10 \%$ & $420 \pm 170$ & $646 \pm 182^{* *}$ & $625 \pm 233^{* *}$ \\
\hline
\end{tabular}

Note: compared with the control group, * refers to $\mathrm{p}<0.05$ and $* *$ refers to $\mathrm{p}<0.01$.

A large number of studies indicated that, a large amount of lactic acid could be produced in the body during exercises through respiration. The increase of lactic acid could promote the fat flow, which could then produce muscle tissues. The increase of muscle tissues could promote the body metabolism (Wang et al., 2014; Fu et al., 2009). As shown in table 3, in the rest state, there was no significant difference in the content of blood lactic acid between the control group and three experimental groups. Then 20 minutes after the swimming, the content of blood lactic acid of mice in experimental group three decreased significantly compared with that of the control group $(p<0.05)$. In the meantime, the content of blood lactic acid of mice in experimental group one and two also decreased but not as significant as that of experimental group three $(\mathrm{p}<0.01)$. Fifty minutes after the swimming, the content of blood lactic acid of mice in three experimental groups was significantly lower than that of the control group, which also showed a dose-effect relationship. Besides, 20 minutes after the swimming, the increment of blood lactic acid of mice in experimental group two and three was significantly lower than that of the control group. Therefore, the effect of asparagus extract solution on the blood lactic acid content of mice was in laddering form. In addition, there was an extremely significant difference between the non-taking group and the high dose group. Thus, the higher the concentration of asparagus extracts solution was, the more the metabolism ability could be improved.

As shown in figure 2, after intense exercises, a large number of free radicals were produced, resulting in a short supply of muscle glycogen. As a representative product of the lipid peroxide, the content of muscle glycogen could objectively reflect the production level of free radicals in the body $(\mathrm{Fu}$, 2009). The content of muscle glycogen of the mice in experimental group one decreased significantly $(\mathrm{p}<0.01)$, while that of experimental group two and three decreased slightly $(p<0.05)$. Hepatic glycogen is an important kind of antioxidant enzyme that clears free radicals away from the body, which can 
disproportionate oxygen and produce water. The content of hepatic glycogen of the mice in experimental group two and three showed an increasing tendency $(\mathrm{p}<0.05)$, while that of the mice in experimental group one increased significantly $(p<0.01)$. After the intake of asparagus extracts solution, the content of hepatic glycogen and muscle glycogen increased. This indicated that in the exercising state, though the content of hepatic glycogen and muscle glycogen could increase or decrease relatively, the reservation of hepatic glycogen and muscle glycogen in the body increased as a whole. The decomposition of muscle glycogen was accelerated during exercising and thus the metabolism was promoted.

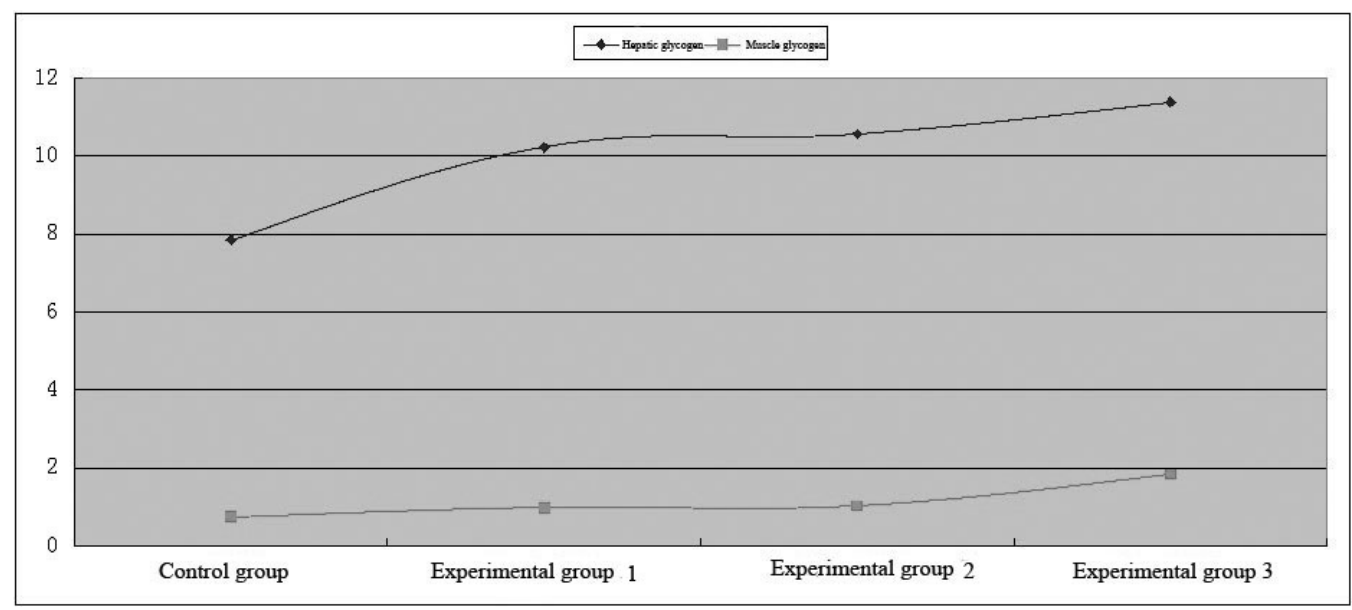

Figure 2. Content of hepatic glycogen and muscle glycogen

Analysis of the constituents of ethanol extracts of asparaguses showed that, the content of total saponins accounted for $18.3 \%$, the content of the total sugar accounted for $14.91 \%$ and the content of the total amino acids accounted for $13.33 \%$. The asparaginic acid and glutamic acid were the main amino acids in asparagus extracts.

The asparaginic acid belongs to excited amino acids, which can improve the cardiac contractile function, reduce oxygen consumption as well as eliminate fatigue (Wen et al., 2015). Moreover, the asparaginic acid is an important functional component of asparagus extracts. Therefore, the asparagus can be scientifically and effectively used to produce products that can promote metabolism.

Metabolic disorders are caused by the accumulation of metabolic substances like lactic acid due to the excessive consumption of body energy (Pan, 2007). Experiments in this study indicated that, the intake of asparagus extracts could increase the content of calcium, vitamins and micro-elements in the body of mice. Sugar is an important energy source of muscle tissues. In short-time but intense exercises, the energy of muscle tissues is mostly supplied by 
glycometabolism (Huang et al., 2009; Liu and Zhang, 2001). However, in longtime but low-intensity exercises, the energy is supplied firstly by sugar oxidation. Thus the reservation and metabolic capability of muscle glycogen are important factors that determine tolerance (Zhao et al., 2016). A large number of studies show that the exercise-induced physical exhaustion happens concurrently with the exhaustion of muscle glycogen (Wei et al., 2003). As muscle glycogen consumption increases, the hepatic glycogen is consumed to maintain the blood glucose of body. Thus the content of hepatic glycogen decreases. Therefore, the content of muscle glycogen and hepatic glycogen are sensitive indexes that reflect the fatigue degree (Shi et al., 2005). Experiments in this study showed that the intake of ethanol extracts solution of asparaguses could significantly increase the content of hepatic glycogen in mice, improve the exercise ability of the body as well as promote the body metabolism.

\section{CONCLUSIONS}

In this study, the alcohol extraction solution of asparagus is taken as the research object and analysis shows that the content of amino acid reaches up to $42.26 \mathrm{mg} / \mathrm{kg}$, which contains about 17 kinds. The content of asparaginic acid accounts for about $20 \%$, while that of glutamic acid accounts for about $15 \%$. Meanwhile, the content of leucine, isoleucine, alanine and lysine, etc., is also very high. In addition, the asparagus is also rich in saponin and polysaccharide, in which the content of saponin is $18.3 \%$ and the content of polysaccharide is $14.91 \%$. The content of fat is only $2.04 \%$. In conclusion, the asparagus extracts can resist fatigue and promote metabolism. Meanwhile, they have high values in being developed into health care foods, which play an important role in regulating body metabolism as well as regaining energy of athletes. Besides, the experimental results in this study can provide an experimental basis for the production of asparagus products that can promote body metabolism in the future.

\section{ACKNOWLEDGEMENTS}

The paper was supported by the Shannxi Province Social Science Fund (2015P004) and the Science Fund of Xi' an University of Technology and Architecture (RW1504).

\section{REFERENCES}

1. Fu J. L. (2009). Rutin effect for liver glycogen and muscle glycogen of ICR mice. Medical Information, 22 (6), 958-960.

2. Fu L., Liu F. \& Huo G. C. (2009). Research advance of Lactococcus lactis of oxidative stress resistance. Journal of Northeast Agricultural University, 40(6), 132-136. 
3. Hu J. W., Lu S. M. \& Lu P. (2007). A probe into normal levels of hematological and biochemical indexes in 10 kinds of common spf rats and mice. Laboratory Animal Science. 24(2). DOI: 10.3969/j.issn.10066179.2007.02.002.

4. Huang L. Q., Liang F. \& Chen C. (2009). Mechanism and index evaluation method for endurance endurance exercise. Journal of Yulin Normal University, 30 (3), 101-103.

5. Jia S. P. (2007). Integrated processing of asparagus. China rural science and technology, (2), 24-25.

6. Ju Y. D. (2011). The chemical constituents and pharmacological effects of Asparagus officinalis. China horticultural abstracts, 27(2), 125-126.

7. Liu X. L. \& Zhang X. H. (2001). Research progress on short time, high intensity and intermittent movement of glucose. Chinese Journal of tissue engineering, 5(19), 126-127.

8. Luan G. C., Wang J. Q. \& Bu D. P., et al., (2007). Review: polyunsaturated fatty acids (pufas) regulation of genes expression of lipid metabolism. China Animal Husbandry \& Veterinary Medicine, 34(12), 5-8.

9. Pan J. L. (2007). Energy metabolism characteristics of sprint training and nutrition and recovery of athletes. Journal of Hunan Agricultural University: Social Science Edition, (1), 61-62.

10. Shi L. P. \& Ma D. M., et al. (2005). The solution of Lifang, exhaustive exercise on mice liver ultrastructure and glycogen content of muscle glycogen of liver for the experimental study on the root of Baji. Liaoning Journal of traditional Chinese medicine, 32 (9), 971-973.

11. Sun X. H., Shi G. B., Ye A., Da M. H. \& Zhao M. H. (2012). Experimental study on the anti-stress function and anti-fatigue property of shenqi wuwei chewable tablets. Pharmaceutical Journal of Chinese People's Liberation Army, 28 (5): 411-414. DOI: 10.3969/j.issn.10089926.2012.05.10.

12. Tang J., Zheng S. B. \& Zhu J. K. (2011). Extraction and determination of Rutin in Asparagus (NATURAL SCIENCE EDITION). Journal of Qiqihar University, 27 (4): 42-46. DOI: 10.3969/j.issn.1007984X.2011.04.014.

13. Tian Y. G., Zhang H. \& Huang Y. M., et al. (2013). The immune function of asparagus extract and active ingredients from ethanol on. Food Science, 34 (1), 277-280.

14. Wang F., Zhang Z. J. \& Li H. Z. (2014). Respiration metabolism for lactic acid bacteria. Journal of Anhui Agricultural University, 41(2), 228- 
233.

15. Wei S. G., Yang Z. Y. \& Gao H. (2003). Effects of different training methods and supplement on muscle glycogen biosynthesis in rat. Journal of sports medicine, 22 (1), 35-40.

16. Wen X., Shi S. \& Liu T., et al. (2015). Inhibition of the effect of on acute myocardial infarction in rats. Chinese Journal of emergency medicine, 24 (9).

17. Xie W., Yang Y. L. \& Zheng H. Y. (2004). Experimental study on the effect of extract of Ginkgo biloba on anti fatigue ability of mice. Journal of Shandong Sports Institute, 20 (5), 51-53.

18. Zhang X. F. \& Liu D. D. (2013). Momordica extract of sports fatigue mice anti fatigue effect. Journal of Jilin University: Medical Edition, 39 (3), 494-497.

19. Zhang Y. P., Qu H. X. \& Xie Q. X., et al. (2013). Research progress on main functions and main functions of asparagus and its related species. Food Industry Science and Technology, (4), 363-367.

20. Zhao F. F., Lin W. T. \& Song X., (2016). Aerobic oxidation energy supply system and athletic ability. Chinese sports coaches, 24 (2).

21. Zhao G. C., Zheng Y. \& Li Z., et al., (2012). North of green asparagus cultivation technology. Jilin vegetables, (11), 1-2.

22. Zhu F. N. (2003). Application of mice in biochemistry experiment. Health Vocational Education, 21(1), 10-10. 